\title{
Provider REport of Sustainment Scale (PRESS): development and validation of a brief measure of inner context sustainment
}

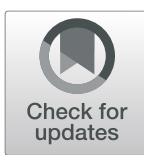

Joanna C. Moullin ${ }^{1,2}$, Marisa Sklar ${ }^{2,3,4}$, Mark G. Ehrhart ${ }^{5}$, Amy Green ${ }^{2,6}$ and Gregory A. Aarons ${ }^{2,3,4^{*}}$ (D)

\begin{abstract}
Background: Implementation scientists and practitioners often rely on frontline providers for reporting on implementation outcomes. Furthermore, measures of sustainment are few, and available sustainment measures are mainly setting or evidenced-based practice (EBP) specific, require organizational and system-level knowledge to complete, and often lack psychometric rigor. The aim of this study was to develop a brief, pragmatic, and generalizable measure for completion by frontline service providers of the implementation outcome, sustainment.

Methods: We utilized a Rasch measurement theory approach to scale the development and testing of psychometric parameters. Sustainment items were developed to be relevant for direct service providers to complete. In order to promote generalizability, data were collected and items were tested across four diverse psychosocial evidence-based practices (motivational interviewing [MI], SafeCare ${ }^{\circledast}$, classroom pivotal response training [CPRT], and an individualized mental health intervention for children with autism spectrum disorder [AIM$\mathrm{HI}$ ) and in four service settings (substance use disorder treatment, child welfare, education, and specialty mental health). Associations between the sustainment measure and sustainment leadership, sustainment climate, and attitudes towards the adoption and use of each of the EBPs were assessed to confirm construct validity.
\end{abstract}

Results: Three items for the Provider REport of Sustainment Scale (PRESS) were assessed for measuring the core component of sustainment: continued use of the EBP. Internal consistency reliability was high. The scale indicated fit to the Rasch measurement model with no response dependency, ordered thresholds, no differential item functioning, and supported unidimensionality. Additionally, construct validity evidence was provided based on the correlations with related variables.

Conclusion: The PRESS measure is a brief, three-item measure of sustainment that is both pragmatic and useable across different EBPs, provider types, and settings. The PRESS captures frontline staffs' report of their clinic, team, or agency's continued use of an EBP. Future testing of the PRESS for concurrent and predictive validity is recommended.

Keywords: Sustainment, Sustainability, Maintenance, Implementation, Measurement, Scale, Psychometric properties, Knowledge translation

\footnotetext{
* Correspondence: gaarons@health.ucsd.edu

${ }^{2}$ Child and Adolescent Services Research Center, 3665 Kearny Villa Rd., Suite 200N, San Diego, CA 92123, USA

${ }^{3}$ Department of Psychiatry, University of California San Diego, 9500 Gilman Drive (0812), La Jolla, CA 92093-0812, USA

Full list of author information is available at the end of the article
}

C C The Author(s). 2021 Open Access This article is licensed under a Creative Commons Attribution 4.0 International License, which permits use, sharing, adaptation, distribution and reproduction in any medium or format, as long as you give appropriate credit to the original author(s) and the source, provide a link to the Creative Commons licence, and indicate if changes were made. The images or other third party material in this article are included in the article's Creative Commons licence, unless indicated otherwise in a credit line to the material. If material is not included in the article's Creative Commons licence and your intended use is not permitted by statutory regulation or exceeds the permitted use, you will need to obtain permission directly from the copyright holder. To view a copy of this licence, visit http://creativecommons.org/licenses/by/4.0/. The Creative Commons Public Domain Dedication waiver (http://creativecommons.org/publicdomain/zero/1.0/) applies to the data made available in this article, unless otherwise stated in a credit line to the data. 


\section{Contributions to the literature}

- This study provides a brief and pragmatic measure of sustainment for completion by frontline providers representing the clinic, team, or agency level, which shows good reliability and validity.

- The Provider REport of Sustainment Scale (PRESS) measures the continued use of an evidence-based practice.

- Provider REport of Sustainment Scale (PRESS) is designed to be adapted and used across different service settings and different evidence-based practices.

\section{Background}

Without sustainment, the public health benefits of the implementation of evidence-based practices (EBPs) will be limited and the accumulated costs from EBP development, evaluation, and implementation are futile. Unfortunately, successful implementation does not guarantee ongoing sustainment [1-3]. In fact, most implementation efforts fail to make it to the sustainment phase [3-6]. The influences and strategies to promote an EBP's sustainment may be unique or distinct from influences and strategies that are effective in previous stages and thus require additional tools and research approaches [7, 8]. Despite acknowledgement of the importance of sustainment, there are multiple reasons why this final phase of the implementation process is less well studied, one of which being a lack of valid, easily accessible, pragmatic measures of sustainment that are appropriate for direct service providers [9-11].

Before moving forward, it is important to note the distinction between sustainment and sustainability. At its core, sustainment addresses the continued use of the practice that is the target of the implementation, whereas sustainability addresses whether the factors are in place to promote that ongoing use. Thus, sustainment can be considered "an outcome of a sustainability effort" [12].

The measurement of sustainment and sustainability has been an ongoing issue in the implementation science literature. Although there are a number of published measures of sustainment and sustainability, existing measures tend to address sustainability rather than sustainment and tend to focus on community public health programs (e.g., smoking cessation campaigns) rather than specific EBPs implemented at an organizational level [8]. In addition, a recent review of published measures of sustainment and sustainability found existing measures tend to be time-intensive, require stakeholders across multiple levels or stakeholders with knowledge across multiple levels to complete, and tend to be limited to assessing a particular EBP or only appropriate for a specific setting [9]. As an example, recently, a 35-item
Sustainment Measurement System Scale (SMSS) [11] was published to assist Substance Abuse and Mental Health Services Administration (SAMHSA)-funded preventative programs. Although this measure was developed with a rigorous process and has a number of strengths, one challenge is that the questionnaire includes the perspective of government administrators and organizational executives who are aware of the "legislation, policies, public-sector fiscal resource availability, bid solicitations, reimbursement schemes, and how these factors are instantiated into service contracts." [13]. Those same individuals may lack intimate knowledge of the day-to-day practice in the clinic. Thus, although such measures have their place and can be useful for a number of purposes, they do not address the providers' assessment of what is happening at the ground level of implementation. Furthermore, they are often too lengthy and involved for many purposes, such as providing a quick and pragmatic assessment of the current state of sustainment. There appears to be no measure that is applicable across health care settings, that can be tailored for particular EBPs, and that is designed to be completed by frontline providers [9].

Our knowledge and understanding of sustainment would benefit from additional measures that are valid, reliable, suitable, and accessible indicators of whether an EBP continues to be delivered. Brief and pragmatic measures of the implementation process are needed to advance implementation theory, identify the mechanisms associated with the sustained use of EBPs, and measure implementation effectiveness [9, 14]. This study is consistent with conceptual models and implementation frameworks such as the Exploration, Preparation, Implementation, Sustainment (EPIS) framework that identify multiple phases or stages in the implementation process [15-18] and include focus explicitly on the sustainment phase $[19,20]$.

The aim of this study was to develop a very brief, pragmatic, valid, and reliable measure of an EBP's sustainment from the perspective of service providers targeting the inner context organizational and provider levels. Specifically, we aimed to (1) generate sustainment items and assess items' face and content validity; (2) conduct Rasch analyses to assess construct validity and item functioning; (3) examine potential demographic, contextual, and nested structure influences (e.g., EBP, position, race, and ethnicity) on item functioning; and (4) examine construct validity by assessing relationships between the sustainment measure and other constructs expected to be associated with sustainment, including sustainment climate, sustainment leadership, and attitudes towards the specific EBP.

\section{Methods}

Scale development proceeded following the approach described by DeVellis which consists of (i) defining the 
construct to be measured, (ii) generating items and the response format by an expert panel, (iii) administering items to a sample, and (iv) evaluating items and optimizing the scale length [21]. We evaluated items using Rasch measurement theory. We also followed Glasgow and Riley's [14] call for the development of pragmatic measures. Table 1 provides the Glasgow and Riley [14] recommendations for pragmatic measures and how each was addressed in the study.

\section{Definitions}

We utilized the core component of the definition of sustainment, "the input(s) (e.g., intervention, program, implementation strategy) continue to be delivered" [9], and focused on actions or processes that would be observable and could be reported on by frontline providers.

Evidence-based practice is defined as "the integration of the best available research with clinical expertise in the context of patient characteristics, culture, and preferences." [22]. This study addresses the sustainment of the specific treatment and interventions that align with that definition (e.g., motivational interviewing). Our focus on EBPs is driven by the shortage of applicable sustainment measures that can be applied in implementation studies of specific interventions proven to improve outcomes and within different service delivery contexts.

\section{Provider REport of Sustainment Scale (PRESS) item generation and response format}

A review of the literature was conducted to create a catalogue of existing measures used in empirical research on sustainment [9]. Constructs represented across all included measures were reviewed and synthesized to facilitate the selection and creation of items assessing continued use. Initially, 5 items were generated by a subset of the authors that targeted EBP usage and provider competence. To strengthen face validity, content validity, clarity, and relevance of the scale, items were reviewed by another subset of authors $(n=3)$ and other stakeholders $(n=3)$ of clinical and organizational psychologists with expertise in implementation science as well as by stakeholders in service settings implementing EBPs, including clinicians. Each reviewer was asked to provide general feedback on the individual items as well as whether additional items should be included. This was a multistep, iterative process until consensus was formed on the items.

To align with other widely used implementation measures, a 5-point Likert-type scale was used across all items such that responses ranged from $0=$ not at all to $4=$ to a very great extent. This response format has been used in multiple implementation measures, including those included to assess construct validity: sustainment climate scale [23], sustainment leadership scale [24], and the Evidence-Based Practice Attitude Scale (EBPAS) [25].

Although they varied slightly across the four samples used in this paper, the basic instructions were as follows: "The following questions ask about [EBP] in your [team/ agency/school]. Please indicate the extent to which you agree with the following items where 0-Not at all, 1- to a slight extent, 2-to a moderate extent, 3-to a great extent, 4-to a very great extent."

\section{Participants}

Items were administered to participants of four existing US National Institutes of Health (NIH) funded studies: (1) a cluster randomized control trial of the Leadership and Organizational Change for Implementation (LOCI) strategy in substance use disorder treatment (SUDT) agencies implementing motivational interviewing [26], (2) a mixed-methods study of EBP sustainment in a state and county child welfare service systems implementing SafeCare $^{\oplus}$ [13], and (3 and 4) the Translating EvidenceBased Interventions for Autism Spectrum Disorder: multilevel implementation strategy (TEAMS) study [27].

Table 1 Required and recommended criteria for pragmatic measures

\begin{tabular}{|c|c|}
\hline Glasgow and Riley criteria & Provider REport of Sustainment Scale (PRESS) \\
\hline Important to stakeholders & $\begin{array}{l}\text { Items and constructs were reviewed by practitioners, supervisors, and other researchers } \\
\text { before data collection }\end{array}$ \\
\hline Burden is low for both respondents and staff & Measure is freely available and takes less than 5 min to complete \\
\hline Actionable & Easy to score and interpret \\
\hline Sensitive to change & $\begin{array}{l}\text { Items are phrased to be sensitive to change and valid across the spectrum of } \\
\text { sustainment }\end{array}$ \\
\hline Broadly applicable & Can be used across different settings and EBPs \\
\hline $\begin{array}{l}\text { Use for benchmark, has norms to interpret, or addresses } \\
\text { public health goals }\end{array}$ & $\begin{array}{l}\text { Informs sustainment of a practice in specific settings so that norms can be developed } \\
\text { and addresses public health }\end{array}$ \\
\hline Unlikely to cause harm & No sensitive information collected \\
\hline Psychometrically strong & Rasch Measurement Theory and Classical Test Theory support reliability and validity \\
\hline Related to theory or model & Covers constructs of EPIS model and existing constructs and definitions of sustainment \\
\hline
\end{tabular}


The TEAMS study looked at the effectiveness of an implementation strategy across two studies that take place in public mental health programs implementing an individualized mental health intervention for autism spectrum disorder, or schools implementing classroom pivotal response teaching (CPRT). In each study, participants were eligible to complete the surveys if they were direct providers of the EBP being implemented or supervisors of those providers.

\section{Survey procedure}

Via the Qualtrics web-based platform, respondents completed surveys between 1 and 5 years following initial EBP implementation. Surveys remained accessible for approximately 1 month such that providers could respond at a time and place of their convenience. Back-up data collection procedures were in place including email follow-up reminders. Consent was obtained from service providers to participate in ongoing surveys of the studies. All studies were approved by the appropriate Institutional Review Boards.

\section{Measures}

\section{Demographics}

Demographic information was collected as part of all of the studies including age, gender, race/ethnicity, and position.

\section{Sustainment Climate Scale (SCS)}

The implementation/sustainment climate measure [23] includes 18 items that assess the degree to which there is a strategic organizational climate supportive of EBP implementation/sustainment. The overall scale in the development study had a Cronbach's alpha of 0.912 and contains the following six subscales: focus, educational support, recognition, rewards, selection for EBP, and selection for openness. This scale was included to assess construct validity because an organizational environment supportive of sustainment was expected to be positively associated with sustainment.

\section{Sustainment Leadership Scale (SLS)}

The implementation/sustainment leadership scale [24] includes 17 items that assess strategic leadership for EBP implementation/sustainment. The measure has an overall Cronbach's alpha of 0.97 and includes the following four subscales: proactive, knowledgeable, supportive, and perseverant. This scale was included to assess construct validity because leadership supportive of sustainment was expected to be positively associated with sustainment.

\section{Evidence-Based Practice Attitude Scale (EBPAS)}

The Evidence-Based Practice Attitude Scale [25] includes 15 items that assess provider attitudes toward adoption of EBP generally. The measure has an overall Cronbach's alpha of .76 and subscale alphas range from .66 to .91 . The measure has been adapted to assess attitudes regarding the adoption of each of the specific EBPs targeted in the parent studies. The measure consists of the following four subscales: requirements, appeal, openness, and divergence [28]. This scale was included to assess construct validity because more positive attitudes towards the EBP were expected to be positively associated with sustainment.

\section{Data analyses}

Data were downloaded into IBM SPSS V25 for data management and preliminary analyses. Initial data were screened for missing data and out-of-range values. Data were cleaned and variable distributions evaluated at both the univariate and multivariate levels.

For Rasch analysis, a sample size of 150 participants is sufficient to calibrate items to within \pm 0.5 logits ( $\alpha$ of 0.01 and $\beta$ of 0.2$)[29,30]$ and with the same power to test for differential item functioning (DIF), where a difference of 0.5 standard deviations within the residuals can be detected for any two groups.

Internal consistency reliability coefficients [21] were calculated to assess reliability using Cronbach's alpha and McDonald's omega [31-33]. The Person Separation Index of the Rasch measurement model was also used, which is equivalent to Cronbach's alpha using the logit value as opposed to the raw score and interpreted in the same way.

Data were fitted to the Rasch measurement model for polytomous response scales [34, 35] using RUMM2030 software [36] and following procedures consistent with key Rasch papers [37-39]. These procedures include assessing (a) fit to the model via fit statistics (item fit residual standard deviations less than 2.5 , person fit residual standard deviations less than 1.5 , and a nonsignificant total chi-square item-trait interaction statistic); (b) ordered item thresholds to determine the appropriateness of items' response options; (c) strategies to improve fit (e.g., item deletion), and subsequent fit statistics; (d) assumption of local independence of items (response dependency with correlations below 0.3 and unidimensionality of scale); (e) generalizability/invariance via examination of differential item functioning (DIF); ( $\mathrm{f}$ ) targeting of the scale; and (g) person separation reliability (as described in the previous paragraph) [39]. The responses to the items were checked to ensure they fit with the metric estimates by analyzing category response/probability curves and category response frequencies. Appropriate steps were taken to order any disordered threshold found, such as collapsing categories, or removing persons or items with poor fit. Bonferroni corrections were applied to adjust the alpha value 
to take into account multiple testing, by dividing the alpha value of 0.05 by the number of items in the scale (3). To check the assumption that there is no pattern of item residuals after extraction of the latent variable, a residual correlation matrix was assessed. Any items indicating response dependency were combined into a subtest. Secondly, unidimensionality of the scale was tested through conducting a principal component analysis of item residuals, performing a test of two subsets of items based on residual patterns, and performing an independent samples $t$-test. No pattern of residuals supported the assumption of unidimensionality. Lack of differential item functioning (DIF) was used to establish measurement invariance across $\mathrm{EBP} /$ settings and demographic variables (e.g., gender, race/ethnicity). The mean "location" score of persons was compared to the item's location to assess how well-targeted the scale was for the sample, with a mean location around zero indicating a well-targeted scale and a positive mean value indicating the sample as a whole was located at a higher level of sustainment than the average of the scale, while a negative value suggesting a lower level.

Finally, correlations between the PRESS sustainment measure aggregated scores and the SCS, SLS, and EBPAS were examined to confirm construct validity. Specifically, the PRESS, SCS, and SLS scale scores were considered as representing unit-level constructs and aggregated to the work group level (school district, clinical group, team) [24, 25, 40, 41, 46]. Intraclass correlation coefficients (ICCs) for work group aggregated scale scores were .50, .22, and .32 for the PRESS, SCS, and SLS, respectively. The EBPAS was similarly aggregated to the work group level. ICCs for EBPAS scales were .03, .12, .09, and .05 for the Divergence, Openness, Appeal, and Requirements subscales, respectively. All scale scores were mean deviated, and correlations between centered scores were examined. We expected a moderately sized correlation between the PRESS and SCS and SLS and small to moderately sized correlations between the PRESS and EBPAS.

\section{Results}

After four iterations with the stakeholder review panel, three items were generated representing continued use of an EBP, analyzed as the PRESS, with two items being removed as they related to fidelity. The resulting PRESS items are shown in Table 2.

We received 527 responses to the scale. The distribution of the surveys varied across studies, with declinations not recorded for SafeCare ${ }^{\circ}$ as it was collected in the field and as such the overall response rate is unknown. Participants were supervisors $(n=59)$ or service providers $(n=468$ clinicians, case managers, and teachers). Participants provided motivational interviewing in substance use
Table 2 Provider REport of Sustainment Scale (PRESS)

The following questions ask about [EBP] in your [setting]. Please indicate the extent to which you agree with the following items

1. Staff use [EBP] as much as possible when appropriate

2. Staff continue to use [EBP] throughout changing circumstances

3. $[E B P]$ is a routine part of our practice

Anchors $0=$ not at all, $1=$ to a slight extent, $2=$ to a moderate extent, $3=$ to a great extent, and $4=$ to a very great extent

disorder treatment (SUDT) $(n=121)$, SafeCare ${ }^{\circ}$ in child welfare $(n=211)$, classroom pivotal response teaching (CPRT) in education $(n=109)$, or an individualized mental health intervention for autism spectrum disorder (AIM-HI) in mental health $(n=86)$ services in multiple counties across California and Oklahoma.

The sample (see Table 3) was $87.6 \%$ female, $35.0 \%$ Hispanic or Latino origin, $62.2 \%$ White, 9.6\% Black or African American, 4.8\% Asian, 3.5\% American Indian/ Alaskan Native, 2.1\% Native Hawaiian/other Pacific Islander, $6.4 \%$ were more than one race, and $11.4 \%$ as

Table 3 Participant characteristics

\begin{tabular}{ll}
\hline Characteristic & Number (\%) \\
\hline Gender & $65(12 \%)$ \\
Male & $461(88 \%)$ \\
Female & 1 \\
Missing/not reported & \\
Age & $124(24.1 \%)$ \\
$20-29$ years & $167(32.5 \%)$ \\
$30-39$ years & $104(20.2 \%)$ \\
$40-49$ years & $119(23.2 \%)$ \\
50 plus & 13 \\
Missing/not reported & \\
Race & $323(62.2 \%)$ \\
White & $50(9.6 \%)$ \\
Black or African American & $25(4.8 \%)$ \\
Asian & $18(3.5 \%)$ \\
America Indian/Alaskan Native & $11(2.1 \%)$ \\
Native Hawaiian/other Pacific Islander & $33(6.4 \%)$ \\
More than one race & $59(11.4 \%)$ \\
Others & 8 \\
Missing/not reported & $184(35.0 \%)$ \\
Ethnicity & 1 \\
Mispanic or Latino & $468(88.8 \%)$ \\
\hline Pring/not reported & \\
\hline
\end{tabular}


others. In total, $24.1 \%$ were $20-29$ years of age, $32.5 \%$ were $30-39$ years, $20.2 \%$ were $40-49$ years, and $23.2 \%$ were 50 years or older.

Internal consistency was high (Cronbach's alpha = 0.947 ; McDonald's omega $=.948$ ) and $85.8 \%$ of the variance in the items was explained by the PRESS scale. The mean inter-item correlation was 0.858. Internal consistency as expressed in Rasch was very good with a PSI of 0.826 with extremes included (people that endorsed all items with a zero or all items with a four) or 0.845 with no extremes [21].

Data were checked for suitability for Rasch analyses. There were no missing values for any item and the minimum and maximum responses were endorsed for all items. The scale indicated fit to the Rasch measurement model with the total chi-square item-trait interaction statistic (19.441) being non-significant $(p=0.078)$ and fit residual standard deviations for items $(0.766)$ and persons (1.458) less than then recommended 2.5 and 1.5, respectively [42] (see Table 4). There appeared to be minimal response dependency, with correlations between all items below 0.3. Thresholds were ordered and no uniform or non-uniform DIF were found across EBP, race, age, gender, or position. Independent samples $t$ tests comparing the person trait estimated on the two most divergent items (item 1 and item 3) showed significant difference $(p<0.05)$ in scores for only 13 of the 527 tests $(2.47 \%)$, providing support of unidimensionality of the scale [42].

The data showed variability in sustainment with the mean person logit scores varying across the studies and EBP being implemented. The mean person logit score was $0.677, \mathrm{SD}=2.553$ (see Fig. 1). Participants implementing SafeCare had a mean logit score of $1.632, \mathrm{SD}=$ 2.05; MI a mean logit score of 0.912, SD =2.26; CPRT a mean logit score of $-0.302, \mathrm{SD}=2.75$; and AIM-HI a mean logit score of -0.72 , SD 2.74. One-way analysis of variance (ANOVA) of total scores indicated significant differences in mean/total sustainment by $\operatorname{EBP}(F(3,523)$ $=149.23, p<.001)$. Special follow-up contrasts were examined to better characterize between EBP differences in sustainment. Significantly greater sustainment was found with SafeCare ${ }^{\ominus}(\bar{x}=3.64)$ than MI $(\bar{x}=2.58)$, $\operatorname{CPRT}(\bar{x}=2.00)$, and AIM-HI $(\bar{x}=1.89)$ combined $(t(526)=20.42, p<.001)$. Significantly greater sustainment of MI than CPRT and AIM-HI combined was found $(t(526)=26.78, p<.001)$. There were no significant differences in sustainment between CPRT and
AIM-HI $(t(526)=0.90, p=.369)$. Age also had a significant effect $(F(3,405)=3.72, p=0.012)$. Overall, participants aged 20 to 29 years had a mean logit score of $0.521, \mathrm{SD}=2.54$; those aged 30 to 39 years a mean logit score of $0.338, \mathrm{SD}=2.7$; those aged 40 to $490.665, \mathrm{SD}=$ 2.35 ; and those aged 50 and over a mean of $1.581, \mathrm{SD}=$ 2.58. Mean sustainment did not significantly differ between supervisors (mean logit score 1.126, SD = 2.02) and providers (mean logit score $0.621, \mathrm{SD}=2.61$ ). The total score statistics held when extreme persons (those who endorsed all items either 0 or 4 ) were removed ( $n=$ 157). Response options for items ranged across the sample's person location distribution (see Fig. 1).

Significant, positive correlations of varying magnitudes were found between the PRESS and all scales with the exception of the EBPAS requirements subscale $(r(66)=.166, p=.182)$. Correlations between the PRESS and the SCS scales varied; correlations were the smallest for reward $(r(98)=.342, p=.001)$ and greatest for overall sustainment climate $(r(98)=.636, p<$ .001). Correlations between the PRESS and the SLS were generally stronger than those with the SCS. Correlations between the PRESS and the SLS scale were the smallest for knowledge $(r(66)=.606, p<.001)$ and greatest for proactive $(r(66)=.779, p<.001)$. Overall, correlations between the PRESS and the EBPAS were comparatively weaker than those with the SCS and SLS. Of the significant correlations between the PRESS and EBPAS scales, magnitudes were smallest with divergence $(r(66)=-.274, p=.026)$ and greatest for appeal $(r(66)=.464, p<.001)$. See Table 5 for correlations.

\section{Discussion}

This study developed and tested a three-item sustainment outcome measure on the use of an EBP suitable for frontline service providers delivering EBPs in the inner context of clinics, teams, and organizations. Internal consistency reliability estimates were high. The scale indicated fit to the Rasch measurement model with no response dependency, ordered thresholds, no differential item functioning, and supported unidimensionality. The PRESS was designed to be usable across different health care and organizational settings, as well as to be tailored for specific EBPs. The PRESS was tested across four diverse EBPs (motivational interviewing, SafeCare ${ }^{\oplus}$, classroom pivotal response training, and an individualized mental health intervention for children

Table 4 Summary of results of Rasch analysis of sustainment within the inner context measure

\begin{tabular}{llllll}
\hline Analysis & Overall model fit & Item fit residual mean (SD) & Person fit residual mean (SD) & PSI [a] & $\%$ Sig. $\boldsymbol{t}$ tests \\
\hline 1. Items $1,2,3$ & $x^{2}=19.441, \mathrm{df}=12, p=0.078$ & 0.766 & 1.458 & 0.826 & $2.47 \%$ \\
\hline
\end{tabular}

$S D$ standard deviation, $\chi 2$ chi-square, $d f$ degrees of freedom, $p$ probability, PSI Person Separation Index

[a] PSI with extremes included ( 0.8445 without extremes) 


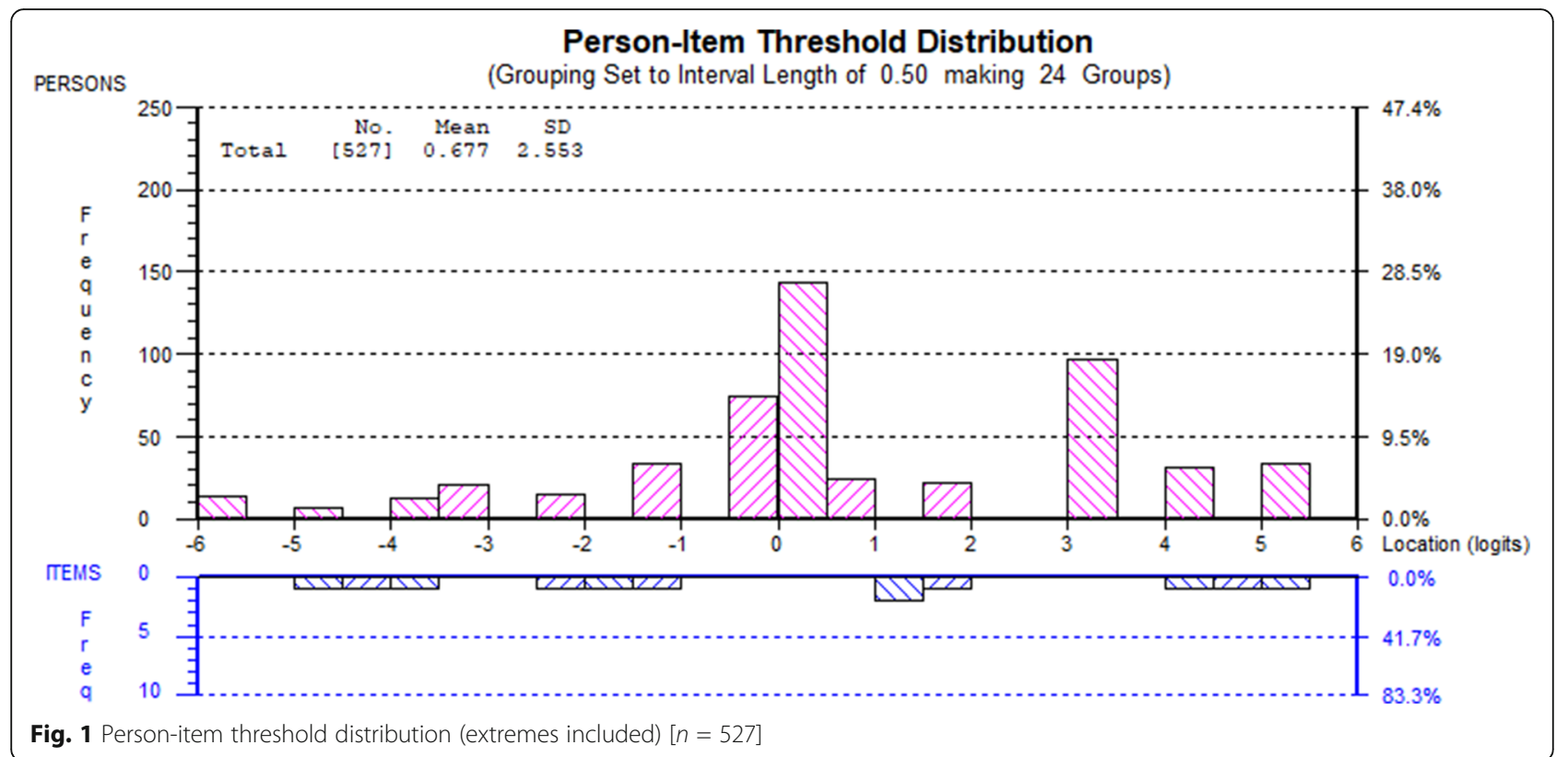

with autism spectrum disorder) and four settings (substance use disorder treatment, specialty mental health, child welfare, and education). By collecting data across these studies, we expanded the variability in agencies, programs, disciplines, settings, and EBPs, thus increasing the generalizability, utility, and its potential to impact implementation science and improving public health across sectors.

All participants had been involved in the implementation of their EBP for at least 12 months; however, the data sets represent different time frames for when the projects started and then moved to the sustainment phase. The EBPs ranged from what could be described as not yet sustained to sustained. In particular, the participants in the SafeCare ${ }^{\circ}$ study had been delivering the practice for 5 years or more and the practice was well integrated into their organizations and routine practice. This was apparent in the results of the scale for this sector. However, it is important to note that the scale also performed well for those where the practice was earlier in the implementation process.

The PRESS complements other measures. As an example, the Sustainment Measurement System Scale (SMSS) is an outcome measure for evidence-based practice broadly (rather than sustainment of a particular EBP) and includes outer contextual knowledge about funding [11]. The PRESS measure on the other hand is specific for the outcome of continued use of a specific EBP and focuses on the provider observation of EBP use, making it pragmatic, generalizable, and suitable for use by practitioners, purveyors, and researchers alike.
The ultimate goal of improving any implementation factor is to increase the implementation and later sustainment of the EBP. With a valid and reliable measure, sustainment can be treated as a dependent variable or as a mediator or moderator of other implementation (e.g., reach/penetration, fidelity) or clinical outcomes (e.g., patient symptoms/behaviors) across studies, facilitating experimental studies of implementation strategies, delineating their mechanisms of action, and potentially contributing to systematic reviews and meta-analyses across studies.

\section{Future recommendations}

Because the sustainment measure was developed to be generalizable across settings, it does not measure the full spectrum of EBP continuation. Furthermore, the measure was used in conjunction with researchsupported implementation/sustainment efforts. It is possible PRESS may function differently in more "real-world" implementation/sustainment efforts. Components of the sustainment variable that are EBP specific, notably sustained fidelity and EBP outcomes (e.g., patient or provider benefits) require tailored assessment. In addition, measures to be completed by higher management or executives relating to outer context sustainment (e.g., funding stability) are suited to a separate measure to ensure respondents are able to answer accurately (e.g., the SMSS [11]). Our recommendation is that PRESS is used in conjunction with other assessments of these components. We also recommend that validation in additional contexts and predictive validity to clinical or service outcomes be evaluated in future research. In terms of criterion 
Table 5 Correlation between Provider REport of Sustainment Scale (PRESS) and Sustainment Leadership Scale (SLS), Sustainment Climate Scale (SCS), and the Evidence-Based Practice Attitudes Scale (EBPAS) scores

\begin{tabular}{|c|c|c|c|c|c|c|c|c|c|c|c|c|c|c|c|c|c|c|c|}
\hline & Mean & $\begin{array}{l}\text { Std. } \\
\text { Dev }\end{array}$ & 1 & 2 & 3 & 4 & 5 & 6 & 7 & 8 & 9 & 10 & 11 & 12 & 13 & 14 & 15 & 16 & 17 \\
\hline 1. PRESS & 2.77 & 1.10 & & & & & & & & & & & & & & & & & \\
\hline 2. SLS Proactive & 3.01 & 1.06 & $.78^{* *}$ & & & & & & & & & & & & & & & & \\
\hline $\begin{array}{l}\text { 3. SLS } \\
\text { Knowledge }\end{array}$ & 3.14 & 1.01 & $.616^{* *}$ & $.85^{* *}$ & & & & & & & & & & & & & & & \\
\hline 4. SLS Support & 3.26 & 0.91 & $.77^{* *}$ & $.82^{* *}$ & $.84^{* *}$ & & & & & & & & & & & & & & \\
\hline $\begin{array}{l}\text { 5. SLS } \\
\text { Perseverant }\end{array}$ & 3.24 & 0.93 & $.78^{* *}$ & $.86^{* *}$ & $.84^{* *}$ & $.92^{* *}$ & & & & & & & & & & & & & \\
\hline 6. SLS Total & 3.16 & 0.90 & $.78^{* *}$ & $.94^{* *}$ & $.94^{* *}$ & $.94^{* *}$ & $.96 * *$ & & & & & & & & & & & & \\
\hline 7. SCS Focus & 3.16 & 0.87 & $.61^{* *}$ & $.84^{* *}$ & $.64^{* *}$ & $.74^{* *}$ & $.78^{* *}$ & $.80^{* *}$ & & & & & & & & & & & \\
\hline 8. SCS Edu Supt & 2.66 & 1.14 & $.437^{* *}$ & $.73^{* *}$ & $.59^{* *}$ & $.62^{* *}$ & $.67^{* *}$ & $.70^{* *}$ & $.74^{* *}$ & & & & & & & & & & \\
\hline $\begin{array}{l}\text { 9. SCS } \\
\text { Recognition }\end{array}$ & 2.18 & 1.08 & $.37^{* *}$ & $.54^{* *}$ & $.38^{* *}$ & $.40^{* *}$ & $.44^{* *}$ & $.47^{* *}$ & $.54^{* *}$ & $.54^{* *}$ & & & & & & & & & \\
\hline 10. SCS Rewards & 1.04 & 1.26 & $.34^{* *}$ & .11 & .01 & .03 & .07 & .06 & .14 & $.27^{* *}$ & $.58^{* *}$ & & & & & & & & \\
\hline $\begin{array}{l}\text { 11. SCS Select for } \\
\text { EBP }\end{array}$ & 2.44 & 1.15 & $.49^{* *}$ & $.70^{* *}$ & $.59^{* *}$ & $.58^{* *}$ & $.70^{* *}$ & $.68^{* *}$ & $.53^{* *}$ & $.49^{* *}$ & $.54^{* *}$ & $.31^{* *}$ & & & & & & & \\
\hline $\begin{array}{l}\text { 12. SCS Select for } \\
\text { Open }\end{array}$ & 2.90 & 0.99 & $.44^{* *}$ & $.68^{* *}$ & $.57^{* *}$ & $.61^{* *}$ & $.67^{* *}$ & $.67^{* *}$ & $.48^{* *}$ & $.46^{* *}$ & $.47^{* *}$ & $.33^{* *}$ & $.82^{* *}$ & & & & & & \\
\hline 13. SCS Total & 2.44 & 0.83 & $.64^{* *}$ & $.80^{* *}$ & $.62^{* *}$ & $.67^{* *}$ & $.75^{* *}$ & $.76^{* *}$ & $.77^{* *}$ & $.77^{* *}$ & $.75^{* *}$ & $.53^{* *}$ & $.85^{* *}$ & $.81^{* *}$ & & & & & \\
\hline $\begin{array}{l}\text { 14. EBPAS } \\
\text { Require }\end{array}$ & 2.9 & 0.95 & .17 & .01 & .09 & .15 & .10 & .08 & .03 & .15 & .12 & .09 & -.23 & -.20 & -.04 & & & & \\
\hline 15. EBPAS Appeal & 3.11 & 0.74 & $.46^{* *}$ & $.30^{*}$ & $.33^{* *}$ & $.41^{* *}$ & $.40^{* *}$ & $.38^{* *}$ & $.38^{* *}$ & $.29^{*}$ & $.42^{* *}$ & $.26^{*}$ & .12 & .14 & $.30^{*}$ & $.62^{* *}$ & & & \\
\hline $\begin{array}{l}\text { 16. EBPAS } \\
\text { Openness }\end{array}$ & 3.22 & 0.67 & $.33^{* *}$ & $.30^{*}$ & $.29^{*}$ & $.32^{* *}$ & $.33^{* *}$ & $.33^{* *}$ & $.37^{* *}$ & .17 & $.34^{* *}$ & .19 & .07 & .14 & .23 & $.29^{*}$ & $.73^{* *}$ & & \\
\hline $\begin{array}{l}\text { 17. EBPAS } \\
\text { Divergence }\end{array}$ & 1.03 & 0.99 & $-.27^{*}$ & -.08 & -.05 & -.16 & -.08 & -.10 & -.18 & .13 & .15 & $.41^{* *}$ & .19 & .12 & .14 & -.19 & $-.32^{* *}$ & $-.31^{*}$ & \\
\hline 18. EBPAS Total & 3.05 & 0.56 & $.40^{* *}$ & .21 & .24 & $.34^{* *}$ & $.28^{*}$ & $.28^{*}$ & $.30^{*}$ & .14 & .21 & .01 & -.10 & -.04 & .08 & $.72^{* *}$ & $.87^{* *}$ & $.73^{* *}$ & $-.65^{* *}$ \\
\hline
\end{tabular}

PRESS Provider REport of Sustainment Scale, SLS Sustainment Leadership Scale, SCS Sustainment Climate Scale, EBPAS Evidence-Based Practice Attitudes Scale ${ }^{* *} p<.01,{ }^{*} p<.05$

Grand means and standard deviations are presented in the first two columns

validity, the PRESS is based on self-report, Likert-type scale, which may not be as objective a measurement as observation; however, it is the benefit of being pragmatic and feasible.

The scale was developed for providers involved in team/agency-level EBP implementation projects. As such, the referent "staff" was used in the items, but equally the referent "our team" may be applicable and consistent with the goal of the scale as developed. The ICC statistics supported aggregation of the PRESS scale to the work group unit level (school district, clinical group, team). Through shared experiences and communication throughout the work group, individual staff likely have similar ideas about the overall sustainment levels across the work group as a whole. Thus, the aggregate scores provide a meaningful indicator of the overall sustainment levels in the work group.

There are occasions when a focus at lower levels may be of primary interest, and there is the possibility for the PRESS items to be adapted for use at an individual level (e.g., physician or patient). For example, items may be adapted for self-ratings of sustainment, such as "I use the [EBP/intervention] as much as possible; (2) I continue to use [EBP/intervention] throughout changing circumstances; (3) The [EBP/intervention] is a routine part of my life." Such a scale could be used to measure the sustainment of individual behavioral change interventions such as mental health, diet, and lifestyle. Similarly, a self-rated version could be suitable for implementation projects in settings where team-level aggregation is not appropriate (e.g., primary care physicians in private practice). As always, such adaptations would require additional psychometric testing.

\section{Conclusion}

The Provider REport of Sustainment Scale (PRESS) responds to the need for a brief, pragmatic, reliable, and valid measure of EBP sustainment [9]. The measure will provide a better understanding of the sustained use of EBPs in organizational settings and subsequently 
enhance the persistence of intended improvements in patient/client outcomes.

\section{Acknowledgements}

Dr. Aarons is core faculty with the Implementation Research Institute (IRI), at the George Warren Brown School of Social Work, Washing University in St. Louis; through an award from the National Institute of Mental Health (R25MH08091607). We would like to acknowledge the sharing of data and collaboration of Lauren Brookman-Frazee and Aubyn Stahmer.

\section{Trial registration}

Not applicable.

\section{Authors' contributions}

JCM, AG, and GAA conceptualized this study. JCM and AG conducted the literature search and initial item selection. MS, ME, and GAA reviewed the items. MS extracted the data and JCM and MS conducted the data analyses. All authors drafted and edited the manuscript. The authors read and approved the final manuscript.

\section{Funding}

This project was supported in part by the US National Institute of Mental Health R03MH1 17493, R01MH072961, R01MH111950, R01MH111981, and National Institute on Drug Abuse R01DA038466 and R01DA049891). The opinions expressed herein are the views of the authors and do not necessarily reflect the official policy or position of the NIMH, NIDA, or any other part of the US Department of Health and Human Services.

\section{Availability of data and materials}

Available upon request of the principal of each of the studies that provided data for the measure development.

\section{Declarations}

\section{Ethics approval and consent to participate}

This was secondary data analysis of studies' data, each of which had their own IRB approvals.

\section{Consent for publication}

$$
\text { Not applicable. }
$$

\section{Competing interests}

GAA is an Associate Editor and JCM is on the editorial board of Implementation Science; all decisions on this paper were made by another editor. The authors declare that they have no other competing interests.

\section{Author details}

"Faculty of Health Sciences, Curtin Medical School, Curtin University, Kent Street, Bentley, Perth, Western Australia 6102, Australia. ${ }^{2}$ Child and Adolescent Services Research Center, 3665 Kearny Villa Rd., Suite 200N, San Diego, CA 92123, USA. ${ }^{3}$ Department of Psychiatry, University of California San Diego, 9500 Gilman Drive (0812), La Jolla, CA 92093-0812, USA. ${ }^{4}$ UC San Diego ACTRI Dissemination and Implementation Science Center (UC San Diego ACTRI DISC), Altman Clinical and Translational Research Institute (ACTRI), 9500 Gilman Drive (0990), La Jolla, CA 92093-0990, USA. ${ }^{5}$ Department of Psychology, University of Central Florida, PO Box 161390, Orlando, FL 32816-1390, USA. ${ }^{6}$ The Trevor Project, PO Box 69232, West Hollywood, CA 90069, USA.

Received: 20 April 2021 Accepted: 16 August 2021

Published online: 30 August 2021

\section{References}

1. Massatti RR, Sweeney HA, Panzano PC, Roth D. The de-adoption of innovative mental health practices (IMHP): why organizations choose not to sustain an IMHP. Adm Policy Ment Hlth. 2008;35(1-2):50-65. https://doi.org/1 0.1007/s10488-007-0141-z.

2. Ament SMC, de Groot JJA, Maessen JMC, Dirksen CD, van der Weijden T, Kleijnen J. Sustainability of professionals' adherence to clinical practice guidelines in medical care: a systematic review. BMJ Open. 2015;5(12): e008073. https://doi.org/10.1136/bmjopen-2015-008073.
3. Wright C, Catty J, Watt H, Burns T. A systematic review of home treatment services. Soc Psychiatry Psychiatr Epidemiol. 2004;39(10):789-96. https://doi. org/10.1007/s00127-004-0818-5.

4. Jacobs SR, Weiner BJ, Reeve BB, Hofmann DA, Christian M, Weinberger M. Determining the predictors of innovation implementation in healthcare: a quantitative analysis of implementation effectiveness. BMC Health Services Research. 2015;15(1):6. https://doi.org/10.1186/s12913-014-0657-3.

5. Nicolaou N, Kentas G. Total quality management implementation failure reasons in healthcare sector. J Health Sci. 2017;5:110-113.

6. MacQueen S, Bradford B. Where did it all go wrong? Implementation failure-and more-in a field experiment of procedural justice policing. Journal of experimental criminology. 2017;13(3):321-45. https://doi.org/10.1 007/s11292-016-9278-7.

7. Shediac-Rizkallah MC, Bone LR. Planning for the sustainability of community-based health programs: conceptual frameworks and future directions for research, practice and policy. Health Education Research. 1998; 13(1):87-108. https://doi.org/10.1093/her/13.1.87.

8. Wiltsey Stirman S, Kimberly J, Cook N, Calloway A, Castro F, Charns M. The sustainability of new programs and innovations: a review of the empirical literature and recommendations for future research. Implement Sci. 2012; 7(1). https://doi.org/10.1186/1748-5908-7-17.

9. Moullin JC, Sklar M, Green A, Dickson KS, Stadnick NA, Reeder K, et al. Advancing the pragmatic measurement of sustainment: a narrative review of measures. Implementation Sci Commun. 2020;1:1-18.

10. Mettert $\mathrm{K}$, Lewis $\mathrm{C}$, Dorsey $\mathrm{C}$, Halko H, Weiner B. Measuring implementation outcomes: an updated systematic review of measures' psychometric properties. Implementation Res Pract. 2020;1:2633489520936644.

11. Palinkas LA, Chou C-P, Spear SE, Mendon SJ, Villamar JA, Brown CH. Measurement of sustainment of prevention programs and initiatives: the sustainment measurement system scale; 2020.

12. Advanced Topics in Implementation Science (IS) Research Webinar Series. In Building a lasting impact: implementation science \& sustainability (Chambers DA ed.: National Cancer Institute; 2013.

13. Aarons $G A$, Green $A E$, Willging $C E$, Ehrhart MG, Roesch SC, Hecht DB, et al. Mixed-method study of a conceptual model of evidence-based intervention sustainment across multiple public-sector service settings. Implement Sci. 2014;9(1):183. https://doi.org/10.1186/s13012-014-0183-z.

14. Glasgow RE, Riley WT. Pragmatic measures: what they are and why we need them. Am J Prev Med. 2013;45(2):237-43. https://doi.org/10.1016/j.a mepre.2013.03.010.

15. Glasgow RE, Vogt T, Boles S. Evaluating the public health impact of health promotion interventions: the RE-AIM framework. Am J Public Health. 1999; 89(9):1322-7. https://doi.org/10.2105/A.JPH.89.9.1322.

16. Damschroder L, Aron D, Keith R, Kirsh S, Alexander J, Lowery J. Fostering implementation of health services research findings into practice: a consolidated framework for advancing implementation science. Implement Sci. 2009;4(1):50-64. https://doi.org/10.1186/1748-5908-4-50.

17. Meyers DC, Durlak JA, Wandersman A. The quality implementation framework: a synthesis of critical steps in the implementation process. Am J Community Psychol. 2012;50(3-4):462-80. https://doi.org/10.1007/s10464012-9522-x.

18. Aarons GA, Hurlburt M, Horwitz SM. Advancing a conceptual model of evidence-based practice implementation in public service sectors. Adm Policy Ment Hlth 2011;38(1):4-23. https://doi.org/10.1007/s10488-010-0327-7.

19. Moullin JC, Dickson KS, Stadnick NA, Rabin B, Aarons GA. Systematic review of the Exploration, Preparation, Implementation, Sustainment (EPIS) framework. Implement Sci. 2019;14(1):1. https://doi.org/10.1186/s13012-018-0842-6.

20. Brookman-Frazee L, Zhan C, Stadnick N, Sommerfeld D, Roesch S, Aarons $G A$, et al. Using survival analysis to understand patterns of sustainment within a system-driven implementation of multiple evidence-based practices for children's mental health services. Frontiers in Public Health. 2018;6:54. https://doi.org/10.3389/fpubh.2018.00054.

21. DeVellis RF. Scale development: Theory and applications. California: Sage publications; 2016

22. American Psychological Association: Policy statement on evidence-based practice in psychology. American Psychological Association; 2005. https:// www.apa.org/practice/guidelines/evidence-based-statement.

23. Ehrhart MG, Aarons GA, Farahnak LR. Assessing the organizational context for EBP implementation: the development and validity testing of the Implementation Climate Scale (ICS). Implement Sci. 2014;9(1):157. https:// doi.org/10.1186/s13012-014-0157-1. 
24. Ehrhart MG, Torres EM, Green AE, Trott EM, Willging CE, Moullin JC, et al. Leading for the long haul: a mixed-method evaluation of the Sustainment Leadership Scale (SLS). Implement Sci. 2018;13(1):17. https://doi.org/10.1186/ s13012-018-0710-4.

25. Aarons GA. Mental health provider attitudes toward adoption of evidencebased practice: the Evidence-Based Practice Attitude Scale (EBPAS). Ment Health Serv Res. 2004;6(2):61-74. https://doi.org/10.1023/B:MHSR.00000243 51.12294.65.

26. Aarons GA, Ehrhart MG, Moullin JC, Torres EM, Green AE. Testing the leadership and organizational change for implementation (LOCI) intervention in substance abuse treatment: a cluster randomized trial study protocol. Implement Sci. 2017;12(1):29. https://doi.org/10.1186/s13012-0170562-3.

27. Brookman-Frazee L, Stahmer AC. Effectiveness of a multi-level implementation strategy for ASD interventions: study protocol for two linked cluster randomized trials. Implement Sci. 2018;13(1):66. https://doi. org/10.1186/s13012-018-0757-2.

28. Aarons GA, Glisson C, Hoagwood K, Kelleher K, Landsverk J, Cafri G. Psychometric properties and United States national norms of the EvidenceBased Practice Attitude Scale (EBPAS). Psychol Assessment. 2010;22(2):35665. https://doi.org/10.1037/a0019188.

29. Linacre JM. Sample size and item calibration stability. Rasch Measurement Trans. 1994;7:328.

30. Pallant JF, Keenan A, Misajon R, Conaghan PG, Tennant A. Measuring the impact and distress of osteoarthritis from the patients' perspective. Health Quality Life Outcomes. 2009;7(1):37. https://doi.org/10.1186/1477-7525-7-37.

31. McDonald RP: Test theory: A unified treatment. New York: psychology press; 2013.

32. Hancock GR, An J. A closed-form alternative for estimating $\omega$ reliability under unidimensionality. Measurement: Interdisciplinary Res Perspectives. 2020;18:1-14

33. Hayes AF, Coutts JJ. Use omega rather than Cronbach's alpha for estimating reliability. But.... Communication Methods and Measures. 2020;14(1):1-24. https://doi.org/10.1080/19312458.2020.1718629.

34. Rasch G. Probabilistic models for some intelligence and attainment tests. Chicago: MESA Press; 1993

35. Andrich D. A rating formulation for ordered response categories. Psychometrika. 1978;43(4):561-73. https://doi.org/10.1007/BF02293814.

36. Andrich D, Lyne A, Sheridan B, Luo G. RUMM2030: A windows interactive program for analysing item response data according to Rasch Unidimensional Measurement Model. Perth: RUMM Laboratory Pty Ltd; 2009.

37. Pallant JF, Tennant A. An introduction to the Rasch measurement model: an example using the Hospital Anxiety and Depression Scale (HADS). Br J Clin Psychol. 2007;46(1):1-18. https://doi.org/10.1348/014466506X96931.

38. Hagquist C, Bruce M, Gustavsson JP. Using the Rasch model in nursing research: an introduction and illustrative example. Int J Nurs Stud. 2009; 46(3):380-93. https://doi.org/10.1016/j.jpurstu.2008.10.007.

39. Tennant A, Conaghan PG. Rasch measurement model in rheumatology: what is it and why use it? When should it be applied, and what should one look for in a Rasch paper? Arthritis Rheum. 2007:57(8):1358-62. https://doi. org/10.1002/art.23108.

40. Bliese PD. Group size, ICC values, and group-level correlations: a simulation. Organizational research methods. 1998; (4):355-73. https://doi.org/10.1177/1 09442819814001.

41. Bliese PD: Within-group agreement, non-independence, and reliability: implications for data aggregation and analysis. In Multilevel theory, research and methods in organizations: Foundations, extensions, and new directions. Edited by Klein K, Kozlowski SWJ. San Francisco: Jossey-Bass; 2000: 349-381

42. Ramp M, Khan F, Misajon RA, Pallant JF. Rasch analysis of the multiple sclerosis impact scale (MSIS-29). Health and Quality of Life Outcomes. 2009; 7(1):58. https://doi.org/10.1186/1477-7525-7-58

\section{Publisher's Note}

Springer Nature remains neutral with regard to jurisdictional claims in published maps and institutional affiliations.

\section{Ready to submit your research? Choose BMC and benefit from:}

- fast, convenient online submission

- thorough peer review by experienced researchers in your field

- rapid publication on acceptance

- support for research data, including large and complex data types

- gold Open Access which fosters wider collaboration and increased citations

- maximum visibility for your research: over $100 \mathrm{M}$ website views per year

At BMC, research is always in progress.

Learn more biomedcentral.com/submissions 